\title{
Description of a program for SAR investigation of the Greenland ice sheet and an example of margin change detection using SAR
}

\author{
Mark A. FAHnestock ANd Robert A. Bindschadler \\ NASA, Goddard Space Flight Center, Greenbelt, MD 20771, U.S.A.
}

\begin{abstract}
In order to interpret changes in the Greenland ice sheet as indications of climatic variation, it is necessary to place observations of local changes in a regional context. This requires a comprehensive monitoring effort which addresses both the inland ice and changes in the ice margin. This paper describes the design of a program for regional investigation of the Greenland ice sheet using synthetic aperture radar (SAR), and discusses the utility of SAR data for detection of change in the ice sheet margin.

Comprehensive coverage of the Greenland ice sheet by ERS-1 SAR will allow us to map the boundaries of snow facies on the ice sheet and investigate recent changes in the ice margin. We will use geo-referenced images to map the current boundaries of snow facies, providing a baseline which can be used to detect future change.

We demonstrate the utility of SAR for detecting recent changes in the ice margin. SAR images clearly show the ice edge, moraines, and ice marginal lakes. These features can be compared with published maps and earlier images in order to document changes in the margin of the ice sheet. We show evidence for recession of a section of the western margin of the ice sheet. The recession, which occurred between 1938 and 1978, ranges from a few hundred meters at high elevations to several kilometers at calving faces in both ice marginal lakes and fjords.

ERS-1 SAR will provide the first opportunity to pursue a comprehensive investigation of the state of the Greenland ice sheet. The ability to address conditions on the ice and to look at margin changes in a systematic way will allow us to develop a stronger framework for interpreting changes in the ice sheet in terms of climatic variation.
\end{abstract}

\section{INTRODUCTION}

Monitoring of ice sheets is an important aspect of global climate studies. One of the most common types of changes reported are those involving shifts in the position of outlet glacier termini. The frequency of such reports is a result of the fact that such changes are often large and easily detected. There are many reasons for this. First, the position of the glacier terminus is very sensitive to changes in ice dynamics upstream (Nye, 1960). Second, the historical record of observations of glacier terminus position is usually longer than observations of less accessible portions of the ice sheet margin. Third, the moraines on the valley walls beside the outlet glaciers provide an easily identifiable measure of changes in the glacier thickness (and position).

To focus exclusively on the changes exhibited by outlet glaciers, however, can strongly bias the inferences of ice-sheet behavior. Their response is a combination of immediate response to changes in the local meteorological environment and delayed response to changes inland arriving at the terminus through complex patterns of ice flow. We argue that what is needed for ice-sheet monitoring is a comprehensive program that collects data on many characteristics over the full extent of the ice sheet. In this paper we describe such a comprehensive program that has just begun and demonstrate some of the types of results to be expected from this program.

\section{MONITORING THE GREENLAND ICE SHEET WITH ERS-1/SAR}

Satellite remote sensing is well suited to the monitoring of the ice sheets because of the synoptic coverage provided. In particular, synthetic aperture radar (SAR) supplies high-resolution image information of the ice sheet in any weather, day or night. Previous analyses of limited amounts of SAR imagery of the ice sheets have shown that many types of features on, and adjacent to, the ice sheet can be identified (Rott and Mätzler, 1987; Bindschadler and others, 1987; Bindschadler and Vornberger, in press; Jezek and others, in press). Of specific interest in monitoring is the ability to detect in SAR imagery the different snow facies, the ice-sheet margin, and marginal moraines (Bindschadler and Vornberger, in press). Because the active parameters of SAR are sensitive to properties which characterize the different facies of the 
ice sheet, it is an ideal instrument for work on the Greenland ice sheet.

The specific goals of our monitoring project are to make systematic use of high-resolution ( $30 \mathrm{~m})$ ERS-1 SAR imagery to determine the position of the boundaries of snow facies on the ice sheet and to look for changes in the ice margin. In anticipation of ERS-1 SAR data of the ice sheet, we use Seasat SAR data to present an example of detection of changes in the ice-sheet margin and describe some useful data sets that have been created as necessary steps in preparation for the utilization of ERS-1 SAR data.

\section{TERRAIN CORREGTION}

In order to produce a geo-referenced data set the elevation distortion inherent to SAR images must be removed. The incidence angle across the swath of ERS-1 SAR data ranges from $20^{\circ}$ at the near-range to $26^{\circ}$ at the far-range. From an altitude of $785 \mathrm{~km}$ this creates a horizontal mislocation of a point in the direction of the satellite from 2.05 times the elevation of the point at the near-range limit to 2.8 times at the far-range limit. The images will be terrain-corrected using a composite digital elevation model produced in Denmark at Kort- og Matrikelstyrelsen by Simon Ekholm (personal commu- nication). Ekholm's model was generated by combining data sets from Geosat radar altimetry, digitized topographic maps of coastal regions, and airborne and preliminary ERS-1 radar altimetry north of $72^{\circ}$ latitude. The terrain-correction algorithm that will be used was developed at the Jet Propulsion Laboratory and will be applied to ERS-1 SAR data by Ron Kwok.

The elevation model is accurate to a few meters over the inland ice south of $72^{\circ}$, a few tens of meters over coastal regions (up to possibly hundreds of meters in very mountainous areas), and many tens of meters over the inland ice north of $72^{\circ}$. Therefore, terrain correction to within a few pixels over most of the inland ice can be expected with significant improvements over the northern half of the ice sheet as radar altimeter data from ERS-1 are reduced. The low surface slope of the ice sheet makes this accuracy well within that required to detect even slight shifts in the elevation of facies boundaries. If the elevation of a facies boundary changes by a few tens of meters, it will move laterally by several kilometers. A change of 100 meters in elevation should result in a large enough shift that the displacement of even a gradational boundary can be detected.

As discussed earlier, the comprehensive ERS-1 SAR coverage of Greenland will enable us to look for regional patterns of advance or recession of the ice margin. The $\mathrm{SAR}$ images of the ice margin will be compared with the

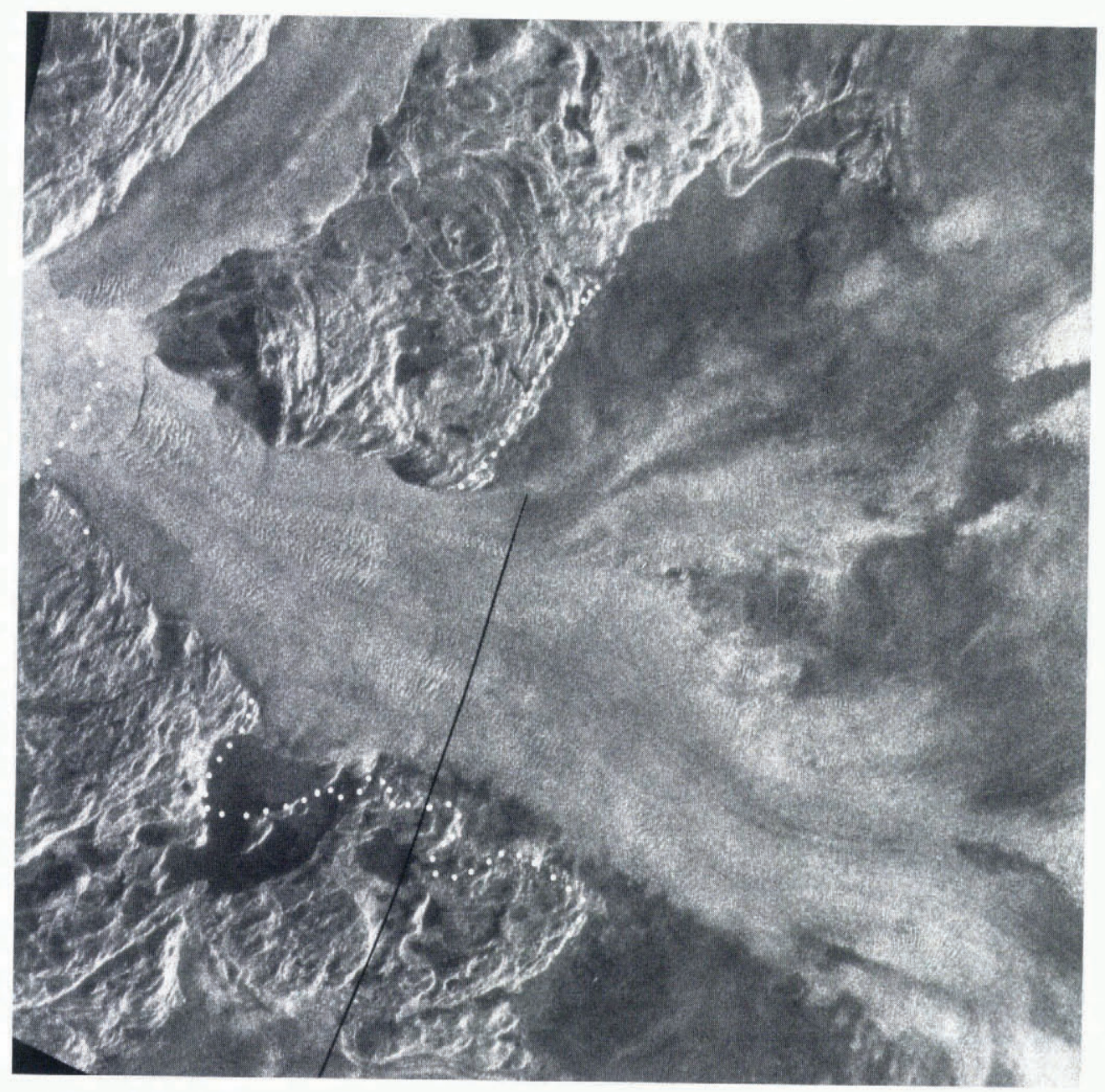

Fig. 1. Seasat image of outlet glaciers in West Greenland, taken 9 October 1978. Dashed line represents the ice margin from 1:250000 topographic map shown in Figure 2. The size of the image is approximately $29 \mathrm{~km}$ on a side. 
position of the ice margin on published topographic maps (1:250000 and 1:100000 map series, Geodætisk Institut, Copenhagen), which are based on aerial photography taken during the middle of this century.

In preparation for comparison with geo-referenced images, the ice sheet boundary on the 1:250000 series topographic maps has been digitized. This data set consists of the geographic coordinates of the ice margin along with a characterization of the boundary as a calving face in fresh water, the calving face of a tidal lobe, the boundary of a nunatak, etc. The density of digitization is approximately ten points per kilometer with a positional accuracy of a few hundred meters $(<1 \mathrm{~mm}$ at $1: 250000)$.

\section{CHANGES IN THE ICE SHEET MARGIN}

In the remainder of this paper, we demonstrate the usefulness of SAR imagery for the detection of changes in the ice margin by comparing a portion of a Seasat image (Fig. 1) with the corresponding 1:250,000 topographic map (Fig. 2). The topographic map was made from aerial photography taken between 1936 and 1938, while the Seasat data were acquired 9 October 1978. The illumination direction for the Seasat image is from the right of the figure.

The position of the ice margin on the topographic map is included on the SAR image as a dashed line. This transfer was accomplished by warping both the SAR image and an image of the topographic map to match a Landsat TM scene (Fig. 3). The quadratic warping removes the first order effects of terrain distortion in the SAR image. The ice margin from the topographic map was transfered to the SAR image by locally matching features near the ice edge such as lakes and streams. A significant fraction of the smaller lakes on the SAR image appear lighter than the larger lakes, presumably because they are ice-covered.

The largest changes evident from this comparison are the retreat and separation of the calving faces in the fjord and the increase in the size of the large lake in the lower left quadrant of the figure. This is consistent with the introductory discussion, which suggested that these parts of the ice edge are the most dynamic. On the topographic map the ice is clearly shown against the island in the large lake and the two outlet glaciers are shown coalescing in the main fjord. In both cases the recession is greater than one kilometer. These changes were first described by

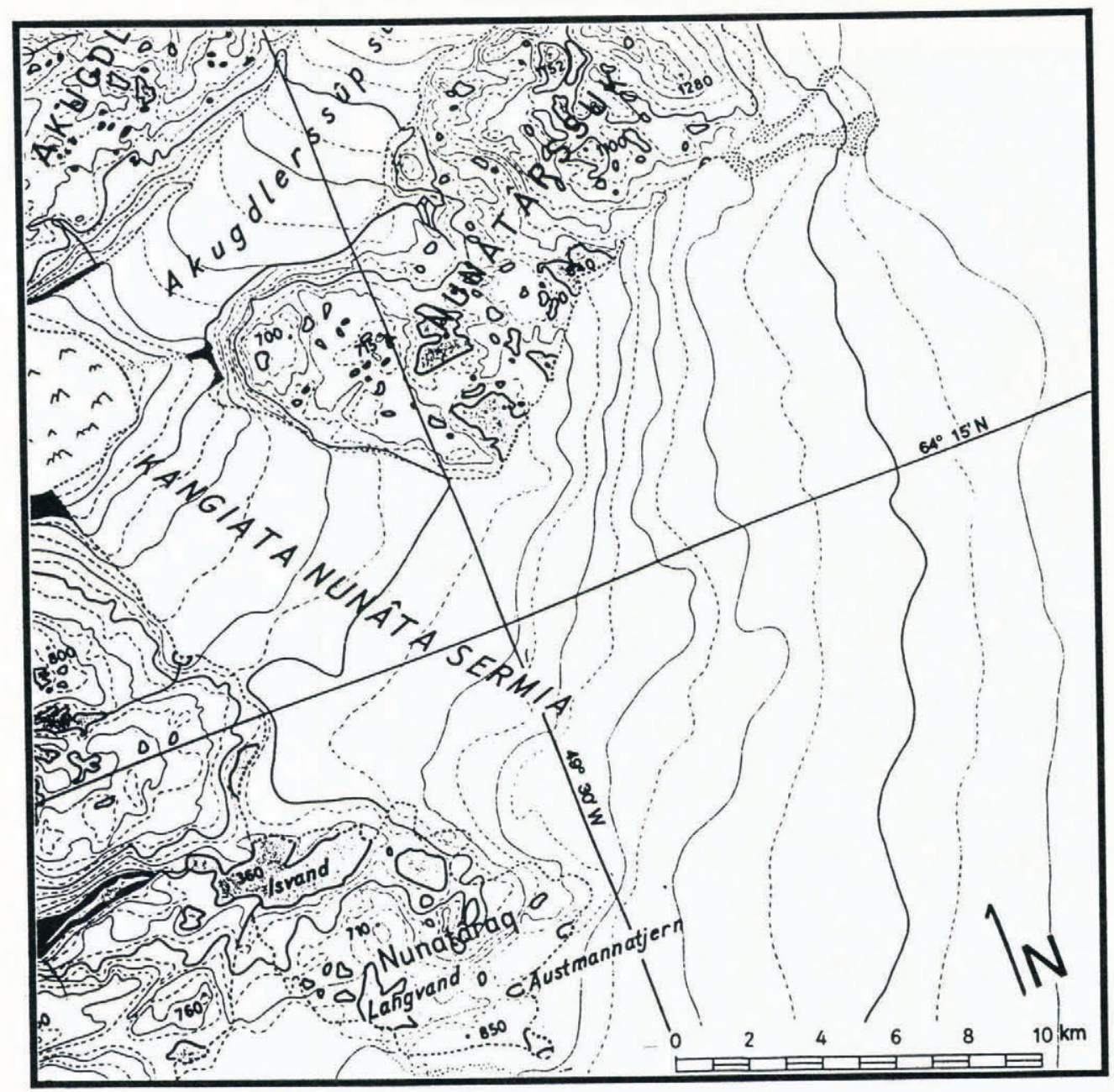

Fig. 2. An excerpt from the 1:250000 topographic map covering the area of Figure 1. The map has been enlarged to match the scale of the image. The map is based on photography taken 1936-38. (1:250000 map series, Geodatisk Institut, Copenhagen, map 64 V.2 Kapisigdlit.) 


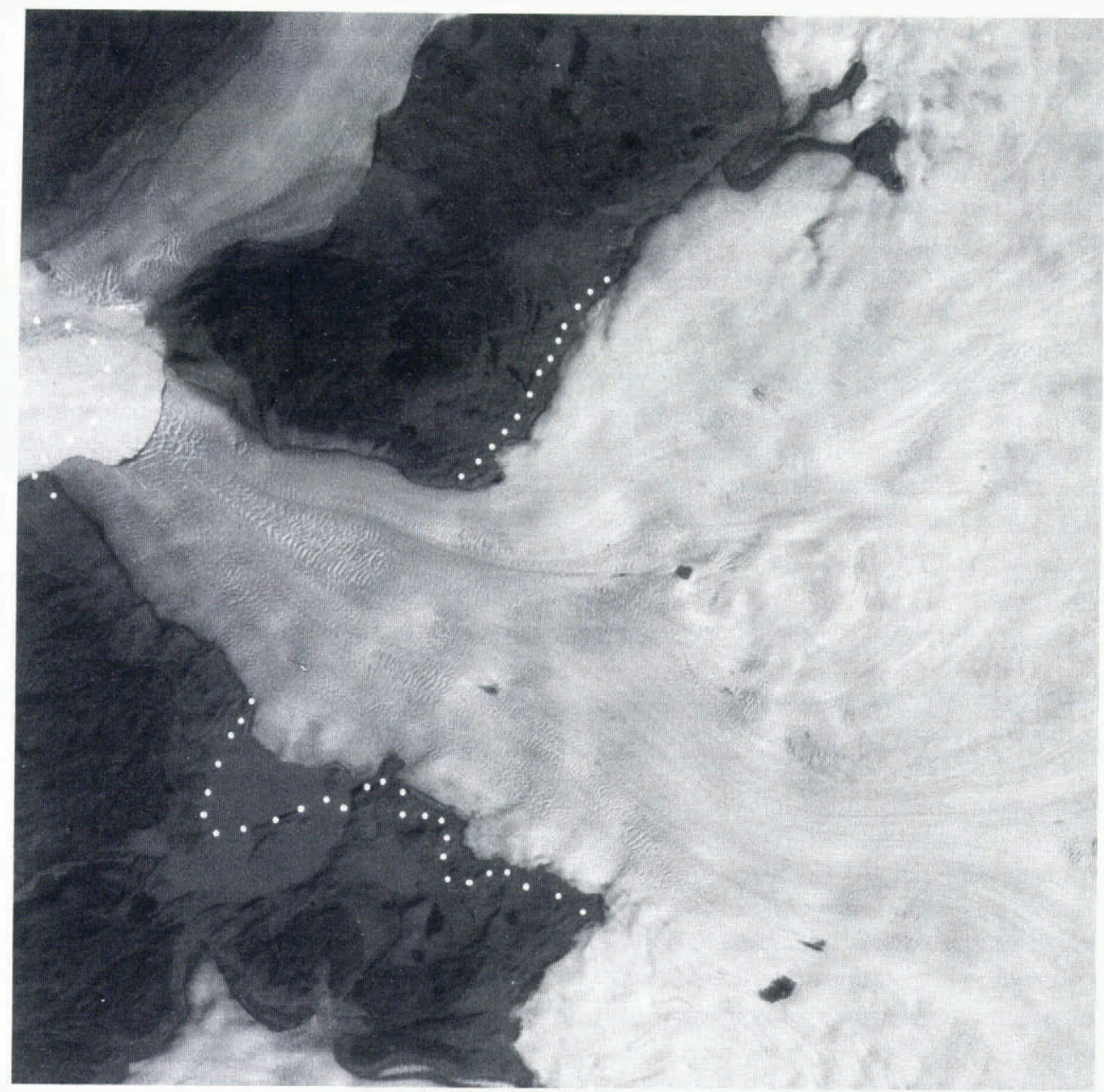

Fig. 3. Landsat Thematic Mapper band 4 image of the area in Figure 1, taken 1 August 1987. In this band, water appears dark. The position of the ice margin is indicated as in Figure 1.

Weidick from aerial photographs taken in 1948 (Weidick, in press).

In other parts of the image, the recession is not as pronounced but is still visible. In the middle of the upper half of the image, the position of the ice margin on the topographic map corresponds to a moraine which appears as a bright curvilinear feature. This moraine forms the shoreline of several lakes which had larger extents on the map, when they were contained by thicker ice. Older moraines which trend at a high angle to the illumination direction form bright features farther up the slope on the left side of the image.

On the bottom of the image, upstream of the large ice marginal lake, there has been a general retreat of between 100 and $500 \mathrm{~m}$ and several tongues of ice have left behind small lakes in the now ice-free areas. The ability to discern a retreat of the margin well upstream from the terminus of Kangiata Nunata Sermia enables us to determine that there must have been a considerable lowering of the ice sheet surface throughout this area rather than a more isolated change limited to the terminus alone, such as would be caused by increased calving.

A Landsat Thematic Mapper band 4 image of the same area is shown in Figure 3. This image was acquired 14 August 1987, nine years after the Seasat image of
Figure 1. The trim lines left by receding ice are more apparent in this image, and it is possible to verify that the curvilinear features from the SAR image are, in fact, moraines. The position of the ice margin on the topographic map has also been indicated on this image.

There are a few changes during the nine years between the two images, the most apparent being the geometry of the embayments in the calving faces of the outlet glaciers. There may also be changes in the levels of some ice marginal lakes, but this could simply be due to a difference in the seasons the images were acquired. One observation, made from a Thematic Mapper band 2 image (not shown), is that it is possible to distinguish those lakes which are turbid and can be assumed to be in communication with the basal water system of the ice sheet; these lakes appear lighter than the clear lakes in this visible wavelength image.

The recession of the ice margin which is discussed above can be related to a general trend for West Greenland described by Weidick (in press). In West Greenland there was a general recession of outlet glaciers starting late in the nineteenth century and progressing most rapidly between about 1920 and the 1950s, with some regions readvancing recently (Weidick, in press). The recession of the outlet glaciers in Figure 1 was 
pronounced, and, as we have described above, recent images indicate a more stable margin.

We would like to emphasize the value of the imagery for regional change detection. The ability to detect changes in all parts of the ice sheet margin is essential because, as we pointed out earlier, concentrating on changes of outlet glaciers alone can distort the interpretation of the regional changes taking place. Further, the use of satellite imagery adds to the historical record of ice margin positions. The regional recession seen in Figure 1 may be related to the longer term, widespread trend mentioned above, while the relative stability suggested by the similarity of the ice positions in the Seasat and Landsat images may more closely reflect the current dynamic conditions.

\section{CONCLUSIONS}

We are starting a comprehensive program to investigate the current state of the Greenland ice sheet. Coverage of the Greenland ice sheet by ERS-1 SAR will allow the distribution of snow facies on the ice sheet to be mapped, providing a valuable baseline in the interior of the ice sheet. Changes in the ice sheet margin will be documented by comparing SAR images to existing maps. We emphasize the need to look for regional changes in the ice margin to provide a more balanced picture than results from observations of variation in outlet glacier termini.

We have found SAR images to be useful for documenting changes in the location of the ice margin as well as changes in ice marginal lakes. Moraines produced during recent advances of the ice sheet show up clearly in SAR imagery. It appears possible to document changes in the ice margin position of a few hundred meters by comparing the position of the margin with the position of nearby lakes and small scale topography on topographic maps. The complicated pattern of variation of the ice margin in the small area discussed in this paper reinforces the conclusion that this type of information needs to be placed in a larger context by investigating as many characteristics of the ice sheet as possible. Only by taking a comprehensive look at the ice sheet can we begin to interpret changes in terms of climatic variation.

\section{ACKNOWLEDGEMENTS}

This work was supported by NASA under grant 578-3502. It was conducted while M.A.F. was a National Research Council-NASA Goddard Space Flight Center Research Associate. We benefitted from the helpful comments of Ted Scambos and two anonymous reviewers.

\section{REFERENCES}

Bindschadler, R.A. and P. Vornberger. In press. Interpretation of SAR imagery of the Greenland ice sheet using coregistered TM imagery. Remote Sensing Environ.

Bindschadler, R. A., K. C. Jezek and J. Crawford. 1987. Glaciological investigations using the synthetic aperture radar imaging system. Ann. Glaciol., 9, 11-19.

Jezek, K. C., M.R. Drinkwater, J.P. Crawford, R.A. Bindschadler and R. Kwok. 1993. Analysis of synthetic aperture radar data collected over the southwestern Greenland ice sheet. F. Glaciol., 39(131), 119-132.

Nye, J.F. 1960. The response of glaciers and ice-sheets to seasonal and climatic changes. Proc. R. Soc. London, Ser. A, 256(1287), 559-584.

Rott, H. and C. Mätzler. 1987. Possibilities and limits of synthetic aperture radar for snow and glacier surveying. Ann. Glaciol., 9, 195-199.

Weidick, A. In press. Greenland. In Williams, R. S., Jr and J. G. Ferrigno, eds. Satellite image atlas of glaciers of the world. U.S. Geol. Surv. Prof. Pap.

The accuracy of references in the text and in this list is the responsibility of the authors, to whom queries should be addressed. 